
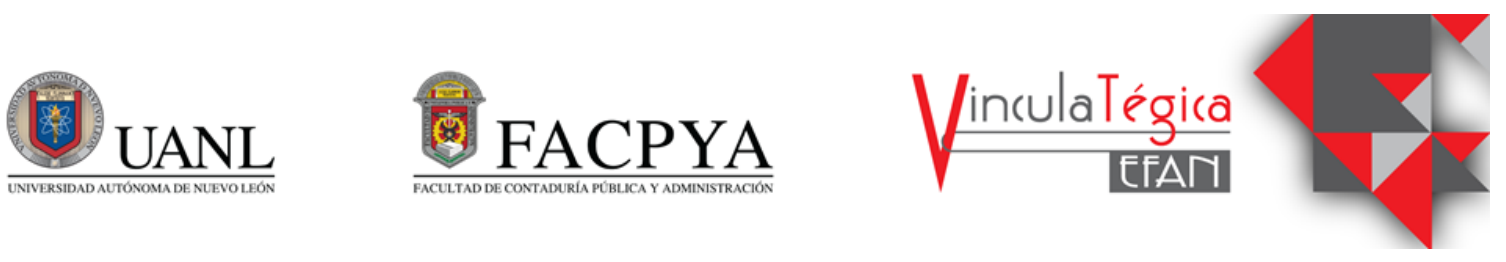

\title{
Análisis comparativo de políticas públicas implementadas ante la contingencia por Covid-19 entre México y el G8
}

\author{
José Luis Sánchez Leyva ${ }^{1}$, Diana Edith Sánchez Zeferino ${ }^{2}$ y Gema Yessenia San Juan- \\ Bernardo $^{3}$ \\ ${ }^{1}$ Universidad Veracruzana. Facultad de Contaduría y Administración. Región Coatzacoalcos - Minatitlán. \\ luissanchez01@uv.mx, Av. Universidad Km. 7.5 CP. 96538. Coatzacoalcos, Ver. 921399594 \\ Universidad Veracruzana. Facultad de Contaduría y Administración. Región Coatzacoalcos - Minatitlán. \\ disanchez01@uv.mx, Av.Universidad Km.7.5 CP.96538. Coatzacoalcos, Ver. 9212115700 \\ ${ }^{2}$ Universidad Veracruzana. Facultad de Contaduría y Administración. Región Coatzacoalcos - Minatitlán. \\ gemayessenia97@gmail.com, Av. Universidad Km.7.5 CP. 96538. Coatzacoalcos, Ver. 9221003184
}

Información del artículo revisado por pares

Fecha de aceptación: junio-2021

Fecha de publicación en línea: diciembre-2021

DOI: https://doi.org/10.29105/vtga7.1-165

\begin{abstract}
Resumen
Abstract

La crisis sanitaria por COVID-19 ha provocado que los países reconfiguren su quehacer institucional e implementen políticas públicas que permitan mitigar la crisis e incentiven la reactivación económica y el bienestar social de la colectividad. El objetivo de este trabajo fue comparar las políticas públicas -bienestar social, fiscal y económica- implementadas por México y el G8 ante la contingencia de salud. Este trabajo se llevó a cabo durante enero y septiembre de 2020 con enfoque cuantitativo, alcance descriptivo de tipo documental, método inductivo-deductivo y corte longitudinal. Los sujetos de estudio fueron los países pertenecientes al G8 y México; el análisis de la información se realizó en matrices que han permitido comparar las políticas públicas en materia de bienestar social, fiscal y económica. Los resultados indican que las políticas en materia de bienestar social relacionadas con el distanciamiento social y el gasto público destinado al cuidado de la salud pública son las que presentan un mayor grado de similitud entre México y el G8; las políticas fiscales relacionadas con la exención y aplazamiento del pago de impuestos así como las relacionadas con el otorgamiento subsidios, préstamos y créditos fueron muy similares tanto en México como en los países del G8. Finalmente, las políticas relacionadas con el sector económico son las que presentaron mayor coincidencia al enfocarse en la

The health crisis caused by COVID-19 has led countries to reconfigure their institutional work and implement public policies that alleviate the crisis and encourage the economic reactivation and social well-being of the community. The objective of this work was to compare the public policies - social, fiscal and economic - implemented by Mexico and the G8 in the face of the health contingency. This work was carried out in January and September 2020 with a quantitative approach, a descriptive scope of documentary type, an inductive-deductive method and a longitudinal section. The subjects of study were the G8 countries and Mexico; The analysis of the information was carried out in matrices which made it possible to compare the public policies of social, fiscal and economic wellbeing. The results indicate that social protection policies related to social distancing and public spending on public health are those that have the greatest similarity between Mexico and the G8; Tax policies related to tax exemption and deferral, as well as those related to the provision of grants, loans and credits were very similar in Mexico and in the G8 countries. Finally, the policies related to the economic sector are those which have shown the greatest coincidence focusing on the reduction of central bank interest rates, the acquisition of
\end{abstract}


reducción de las tasas de interés de los bancos centrales, la adquisición de valores por parte del gobierno y las líneas de crédito que se otorgaron a las empresas afectadas.

Palabras clave: COVID-19, políticas públicas, bienestar social, política fiscal, política económica

Códigos JEL: A11: papel de la economía, I18: política gubernamental, I31: bienestar general, J08: políticas de economía laboral

\section{INTRODUCCIÓN}

A lo largo de la historia han surgido sucesos que pueden representar hechos históricos que marcan de una $\mathrm{u}$ otra manera un antes y un después ya sea para una nación o toda una región del planeta. Tal es el caso de la emergencia sanitaria por COVID-19 que tuvo su origen en el continente asiático a finales del 2019; una situación con alcances globales que ha dejado familias incompletas, miles de desempleados sin posibilidad de sostener sus necesidades básicas, así como un sin número de pequeños empresarios que se han visto obligados a cerrar sus negocios. Incluso, Hevia y Neumeyer (2020) afirman que como consecuencia se espera una profunda crisis para grandes segmentos de la población mundial en el futuro.

Este panorama ha provocado que los gobiernos trabajen de forma intensiva para enfrentar de manera efectiva la crisis sanitaria que sobrepasa las barreras territoriales y obliga a repensar la forma de hacer agendas de buen gobierno relacionadas con bienestar social, políticas fiscales y económicas, para el bien común.

En este sentido, resulta de vital importancia analizar las políticas públicas que cada gobierno ha implementado ante la contingencia presentada por el COVID-19, específicamente México y el G8, durante enero a septiembre de 2020. La información que se presenta es producto del análisis documental a partir de fuentes de información -comunicados e informes de los países analizados-.

\section{MARCO TEÓRICO}

Se entiende al Estado como aquella sociedad conformada por un grupo de personas que se establecen en un territorio determinado que securities by the government and the lines of credit that have been granted to the companies concerned. Key words: COVID-19, public policies, social welfare, fiscal policy, economic policy

JEL Codes: A11: rol of Economics, I18: government policy, I31: general welfare, J08: labor economics policies

desarrolla sus funciones tanto políticas como económicas a través de la creación y organización de relaciones de poder y solidaridad que formaliza en su interior y refleja al exterior (Calduch, 1991). El Estado es una estructura formada por los poderes e instituciones políticas de un territorio, en este caso un país, que se encargan de la administración pública mediante el desarrollo de las políticas necesarias para cada sector que conforma a dicho país o territorio.

La palabra "política" tiene diversas acepciones y se derivan de la complejidad semántica del idioma español. En este sentido, la política (polity) se entiende como la ciencia y arte de gobernar que trata de la organización y administración de un Estado en sus asuntos e intereses (Cadénas \& Ruiz, 2009) mientras que la política (politics) se concibe como la actividad tendiente a la consecución, ejercicio y control del poder político; hace referencia a las acciones, conductas y funciones que realizan personas y grupos con la intención de incidir en el escenario de confrontación política (Jiménez, 2012). Por último, la política (policy) se define como un programa o curso de acción gubernamental (Pastor, 2014). Este último término hace referencia al objeto de estudio en esta investigación.

En cuanto a lo "público", la Real Academia Española (RAE) define lo público como aquello perteneciente o relativo a todo el pueblo; también se entiende como un adjetivo salido del común de la sociedad, relativo al pueblo, común del pueblo o sociedad (Cadénas \& Ruiz, 2009). Lo público hace referencia a aquello que atañe a toda la población de un territorio o país y para quienes se diseñan políticas públicas.

\subsection{Políticas públicas}

El estudio de las políticas públicas 
surge en Estados Unidos como una rama de la administración pública y su finalidad es el perfeccionamiento de las acciones del gobierno (González, 2018) y el estudio de problemas públicos que enfrentan las sociedades contemporáneas (Tórtola \& Monroy, 2020)

De acuerdo con Velásquez (2009) las políticas públicas son un proceso integrador de decisiones, acciones, inacciones, acuerdos e instrumentos, con la participación de una autoridad investida de poder público y de legitimidad gubernamental (Lahera, 2002), encaminado a solucionar o prevenir una situación definida como problemática; Garrido (2008) afirma que las políticas públicas son un conjunto de procedimientos determinados por una dimensión sociopolítica a nivel de su creación, diseño, evaluación y discusión..., así como en la generación de nuevas maneras de distribución del poder, como resultado de su aplicación.

Finalmente, Cadenas y Ruíz (2009) afirman que las políticas públicas son las acciones de gobierno para dar respuestas a las diversas demandas de la sociedad para aliviar los problemas nacionales.

Dentro de los elementos comunes que se pueden identificar en los conceptos anteriores destacan dos principales; el primero, es que el actor que da origen a las políticas públicas es el gobierno o autoridad pública y el segundo, es que se trata de acciones o decisiones encaminadas a dar solución a problemas que se presentan dentro del territorio administrado por dicho gobierno.

En este contexto, la política pública se entiende como el conjunto de decisiones tomadas por el Estado que tienen por objetivo solucionar cualquier situación problemática que se presente dentro de los asuntos públicos y cuyo fin es el bienestar de la colectividad.

Política y política pública tienen que ver con el poder social. Sin embargo, la política tiene un sentido amplio referente al poder del Estado, mientra que, las políticas públicas se refieren a la forma en que el Estado resuelve las problemáticas públicas. Así pues, las políticas públicas son un factor incluido en las decisiones del gobierno y la política es la búsqueda de establecer políticas públicas sobre temas determinados o influir en las mismas (Lachera, 2004).

Pastor (2014) establece una clasificación amplia de políticas públicas que responden a diversos criterios $\mathrm{y}$ definiciones. En ellas, destacan la políticas públicas encaminadas al bienestar de la sociedad (salud), las que se relacionan con reactivación económica, así como aquellas que favorecen una serie de incentivos o procesos regulatorios en materia fiscal. En su elaboración, Arellano y Blanco (2013) establecen cinco fases que se deben tomar en cuenta: entrada a la agenda gubernamental, definición del problema, diseño de la política, implementación y evaluación.

Lo importante en este proceso es posicionar alguna situación problemática en la agenda pública; esto no es más que un proceso a través del cual ciertos problemas o cuestiones llegan a llamar la atención seria y activa del gobierno como posibles asuntos de política pública (Alzate \& Romo, 2017) y posteriormente se trasladan a la agenda gubernamental, tal es el caso de la crisis sanitaria por COVID-19 y cuyos efectos requieren respuestas efectivas de los gobiernos para contener el contagio, buscar el bienestar social y reactivar la economía que favorezca el empleo y el bien común. Las respuestas efectivas a las problemáticas sociales permiten caracterizar las políticas públicas como instrumentos de calidad (Stein \& Tommasi, 2006) que legitiman el poder público.

\subsection{México y el G8}

Los ocho países que integran el G8 son: Alemania, Canadá, Estados Unidos, Francia, Japón, Italia, Reino Unido y Rusia (ITAM, 2006). Las actividades económicas que integran el Producto Interno Bruto (PIB) de estos países son, principalmente, industriales y de servicios (Ministerio de Asuntos Exteriores, 2020); los anuncios oficiales de los primeros casos de COVID-19 detectados así como las primeras medidas expresadas por los gobierno sucedieron en este orden: Japón, seguido por Estados Unidos, 
Francia, Canadá, Alemania, Italia, Reino Unido y Rusia.

De acuerdo con el Ministerio de Asuntos Exteriores (2019), México tiene una población que asciende a 125,200,000 habitantes con un gasto público destinado a la salud muy por debajo comparado con los países que integran el G8. Las actividades económicas en México son fundamentalmente del sector secundario y terciario. El primer caso de COVID-19 se dio a conocer en febrero de 2020 y las principales acciones del gobierno mexicano fueron: restricciones de viaje, distanciamiento social, cierre de escuelas y actividades no esenciales, así como el aumento de los gastos de salud (Fondo Monetario Internacional, 2020).

\section{MÉTODO}

Este trabajo se realizó con enfoque cuantitativo, alcance descriptivo de tipo documental, método inductivo-deductivo y corte longitudinal, durante los meses de enero a septiembre de 2020 .

Los sujetos de estudio fueron los países pertenecientes al G8 y México; el instrumento utilizado para el análisis de la información fueron tres matrices que han permitido comparar las políticas públicas en materia de bienestar social, fiscal y económica que los gobiernos implementaron durante el año 2020 para enfrentar la crisis sanitaria por COVID-19.

\subsection{Objetivos}

- General

Comparar las políticas públicas implementadas por México y el G8, ante la contingencia presentada por el COVID-19, en el periodo eneroseptiembre de 2020.

- Específicos

- Identificar las políticas en materia de bienestar social implementadas por los gobiernos México y el G8.

- Identificar las políticas en materia fiscal implementadas por los gobiernos México y el G8.
- Identificar las políticas de índole económico implementadas por los gobiernos México y el G8.

- Contrastar similitudes, diferencias y resultados de la aplicación de las políticas públicas implementadas.

\subsection{Planteamiento del problema}

Transcurría el mes de diciembre de 2019, cuando el brote de casos de lo que en ese entonces se denominaba una "neumonía atípica" ponía en que pensar a los médicos de la ciudad de Wuhan, provincia de Hubei, en China. Los primeros estudios relacionados a este padecimiento mostraron que su nivel de propagación era alto, por lo que el número de personas contagiadas cada vez era mayor. Además, dichos estudios mostraban que el virus afectaba de una manera más agresiva a los adultos en un rango de edad de 30 a 79 años y presentaba, hasta el momento una tasa de mortalidad global de 2.3\% (Díaz \& Toro, 2020).

Durante los meses de enero y febrero de 2020 el brote comenzó a expandirse en otras regiones del país de manera vertiginosa y continuó así en otros países del continente asiático para luego tener presencia en el resto de los continentes. En marzo de 2020, la Organización Mundial de la Salud (OMS) se pronunció al respecto para reconocer al COVID-19 como una pandemia e incitó a cada uno de los gobiernos de los países afectados a tomar medidas en contra de lo que se considera la mayor emergencia relacionada con la salud pública ocurrida en nuestra época.

En lo que respecta a los países pertenecientes al G8, no fueron la excepción y el surgimiento de los primeros casos se dio a conocer casi al mismo tiempo en cada uno de ellos. Tal es el caso de Japón que fue el primero en anunciar que existía un primer caso confirmado dentro de su territorio. El segundo país en confirmar su primer caso fue Estados Unidos, para luego seguirle Francia, Canadá y Alemania, Italia, Reino Unido y Rusia. La propagación no se pudo evitar a pesar de que la mayoría de estos países habían implementado sus propias medidas de 
contención y restricción de ingreso en su territorio, así como políticas públicas en el ámbito de salud pública, en materia fiscal y económica.

El G8 tomó decisiones conjuntas y la principal política que se impuso, fue la del distanciamiento social, así como la inversión de una porción del PIB en la preparación y obtención de equipo de salud para prepararse ante la inminente saturación de hospitales. En materia fiscal, las políticas más representativas fueron las relacionadas con el aplazamiento del cobro de impuestos con el objetivo de apoyar a los empresarios y trabajadores afectados por la pandemia. En el ámbito económico las políticas públicas se dirigieron a la aprobación de paquetes económicos destinados al apoyo de la economía de las empresas y familias de dichos países. Además de que los bancos principales de cada país decidieron bajar las tasas bancarias y congelar los pagos de préstamos y tarjetas de crédito por hasta tres meses.

En el caso de México, este dio a conocer la aparición de su primer caso confirmado en febrero de 2020. A partir de entonces las políticas de distanciamiento social como las restricciones de viaje, cierre de escuelas y actividades no esenciales no tardaron en ser pronunciadas y con ellas la declaración de emergencia sanitaria; todo esto con el objetivo de asegurar que el Sistema de Salud contara con los recursos suficientes para la adquisición de equipo y materiales médicos, así como apoyar a hogares y empresas. En materia fiscal, las principales políticas implementadas fueron el anticipo de pagos en pensiones así como la agilización de los procesos de adquisiciones y devoluciones del IVA y el otorgamiento de préstamos a empresas y trabajadores del sector formal e informal.

Así también, se crearon políticas en el ámbito económico como recortar la tasa bancaria, aplazar el pago de préstamos y créditos, además de la detención de remuneraciones a accionistas de instituciones bancarias y aseguradoras. Además, una medida importante de mencionar es la reasignación de los gastos no primordiales y la reducción de salarios a servidores públicos de altos rangos.

En este contexto, resulta importante identificar qué similitudes y diferencias se encuentran en las políticas públicas implementadas por México y el G8 ante la contingencia presentada por el COVID-19, en el periodo enero-septiembre de 2020

\subsection{Justificación}

La presente investigación se enfocó en el análisis comparativo de las políticas públicas aplicadas en México y el G8 para enfrentar la contingencia sanitaria por COVID-19. Este trabajo se realiza como respuesta a la observación de los grandes efectos que se han presentado como resultado ya sea directo o indirecto del problema planteado en todos los ámbitos, ya que al ser un hecho sin precedentes en nuestra época, ha tomado por sorpresa a toda la población, que por lo tanto presenta una creciente necesidad de tener a su disposición la mayor cantidad de información obtenida de estudios y análisis de dicha situación para entenderla y ser consciente de lo que está pasando alrededor del mundo.

Si bien, para más de una persona el hecho de que el tema seleccionado sea de actualidad también es cierto que existen una variedad de fuentes que permiten el desarrollo correcto de la investigación y posterior análisis de los datos derivados de la misma. En el caso específico del presente trabajo, se contó con las herramientas suficientes para la obtención de información proveniente de autores con amplio conocimiento sobre el tema, encontrados gracias a un arduo trabajo de investigación y selección adaptado a esta nueva situación y forma de trabajar a la que se le conoce como "nueva normalidad".

Aunado a eso, su principal aporte es el valor de la información que se obtuvo como resultado de su ejecución, que bien se puede decir que es nueva en todos los sentidos, dado que un análisis de esta naturaleza aplicada en este contexto específico contribuye de gran manera a la generación de conocimiento.

\subsection{Instrumento}

La información obtenida se clasificó y analizó mediante el uso de matrices de 
comparación de elementos organizados por categorías en materia de políticas públicas de bienestar social, fiscal o económico.

Dichas matrices están compuestas de filas y columnas. En el caso de las columnas se colocan los elementos que identifican las políticas públicas -bienestar social, fiscal o económico- y en las filas se ubican los países de los cuales se recopiló la información.

Para el caso de las políticas públicas en materia de bienestar social se integraron los siguientes rubros: salud, seguridad social, educación, vivienda y apoyos sociales, así como se observa en la tabla 1. 
Tabla 1 Matriz de comparación de políticas públicas en materia de bienestar social

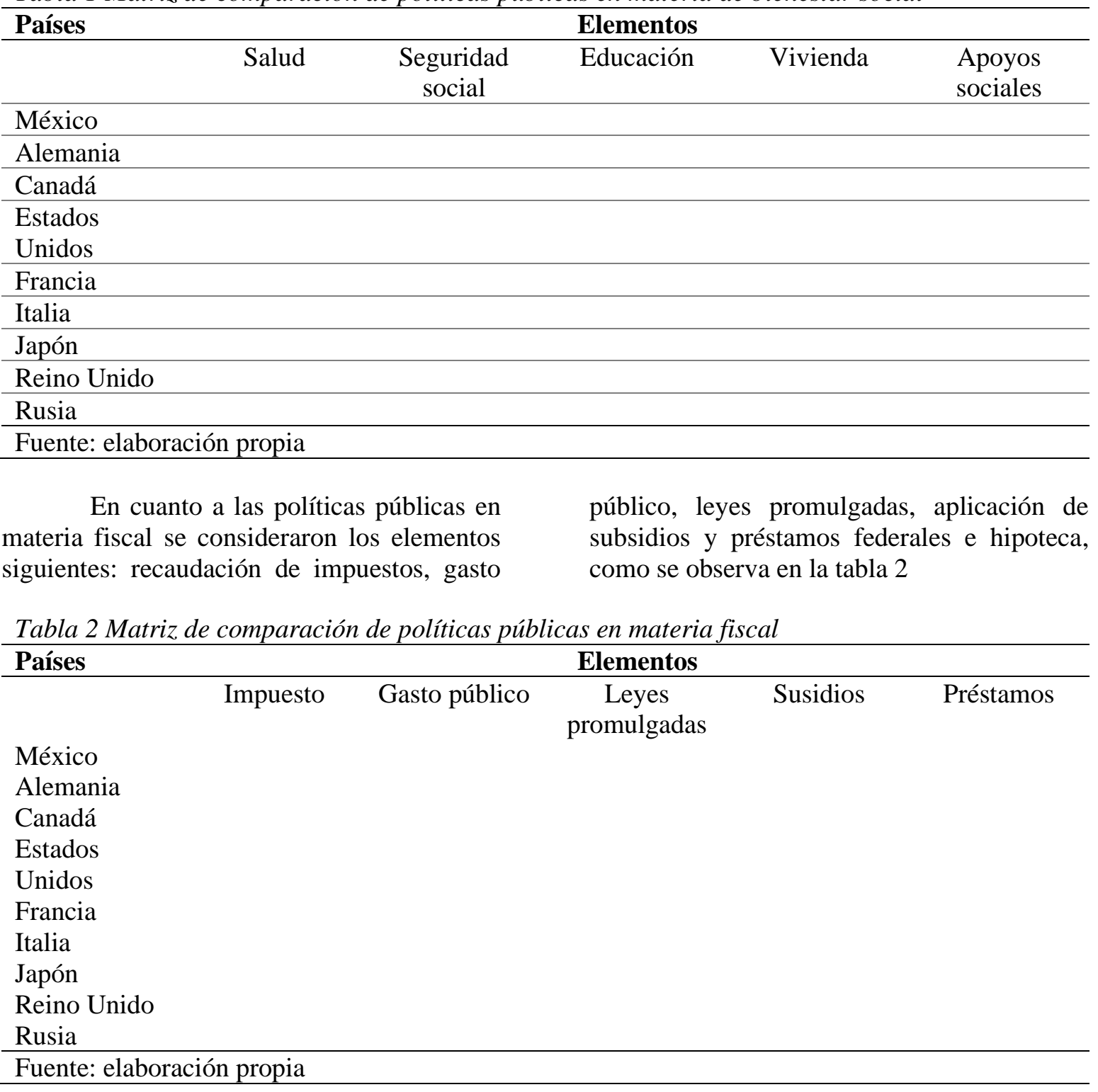

En cuanto a las políticas públicas en materia económica, se tomó en cuenta lo siguiente: tasa de interés bancaria, paquetes económicos, compra de valores, reserva federal, así como líneas de credíto, como se observa en la tabla 3. 
Tabla 3 Matriz de comparación de políticas públicas en materia económica

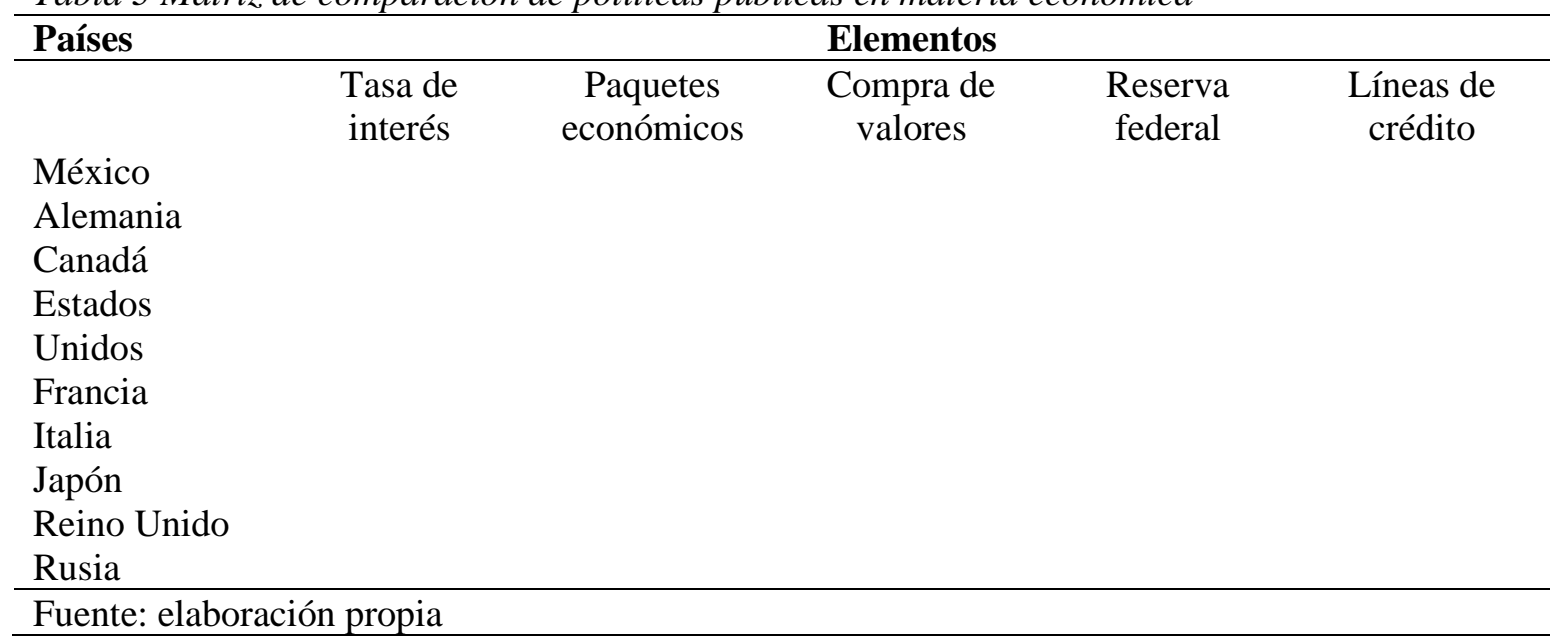

\section{RESULTADOS}

Los datos analizados en la presente investigación fueron obtenidos a través de un proceso de revisión de distintas fuentes de consulta entre las que destacan el Fondo Monetario Internacional (FMI), la Organización Internacional del Trabajo (OIT), informes de los departamentos de Estado, así como notas periodísticas que fueron analizadas en un principio, para después identificar las principales medidas implementadas por los países y políticas públicas aplicadas. Una vez que se recolectó la totalidad de la información se pudo realizar una selección de aquellas medidas que representan de mejor manera las acciones que cada país consideró pertinente decretar en sus territorios.

Al realizar el análisis comparativo se puede afirmar que el conjunto de políticas implementadas por México y los países que integran el G8 presenta varias semejanzas principalmente en decisiones relacionadas con el bienestar social (ver anexo 1); destacan las medidas de distanciamiento así como cierre de escuelas, también en las que tienen que ver con el aumento de inversión en el sector salud para el abastecimiento de los suministros necesarios para hacer frente a la contingencia.

$$
\text { Las principales diferencias }
$$

encontradas se pueden atribuir al nivel de desarrollo de estos países; quienes integran el G8 adoptaron medidas parecidas en cuanto a los apoyos sociales brindados a su población ya que éstos se enfocaron en brindar subsidios $\mathrm{y}$ beneficios a las empresas afectadas y personas que perdieron sus empleos debido a la pandemia, así como en algunos casos suspender los pagos de rentas y servicios públicos. Por otro lado, el gobierno mexicano centró sus esfuerzos en apoyar a microempresas y aquellas personas beneficiadas con programas sociales desde antes del inicio de la pandemia, por lo que los beneficios llegaron a un número reducido de personas en comparación con los países del G8.

Ahora bien, la matriz de comparación de las políticas públicas implementadas en materia fiscal (ver anexo 2), por los países del G8 y México, para enfrentar la contingencia por COVID-19 refleja en la mayoría de los países pertenecientes al G8 el interés por las exenciones o aplazamientos en los pagos de impuestos como principal estrategia de ayuda a los contribuyentes. También se otorgaron subsidios para empresas con el objetivo de preservar la mayor cantidad de empleos.

Otro sector en el que se puede observar mayor número de acciones es el relacionado con el aplazamiento en los pagos relacionadas con préstamos o créditos que los ciudadanos tienen con instituciones bancarias, así como hipotecas en el caso específico de Estados Unidos. Cabe destacar que en este grupo solo Canadá y Estados Unidos promulgaron leyes específicas como una de sus estrategias para combatir los estragos de la 
pandemia.

Por otro lado, México también adoptó medidas relacionadas con la entrega de préstamos personales y para empresas con bajas tasas de interés así como el aplazamiento de los pagos de créditos. Pero, a diferencia de los países del G8, México concentró sus esfuerzos en la agilización de los procesos de licitación para el gasto público así como dar prioridad en los asuntos urgentes dejando de lado aquellos que podían ser aplazados. Algo destacable fue que solo en México se tomó la decisión para disminuir sueldos de los servidores públicos de los niveles más altos con el fin de darle un uso distinto a esos recursos y así aumentar la cantidad de presupuesto disponible para el resto de las medidas en contra del COVID-19.

En cuanto a las políticas públicas implementadas en materia económica (ver anexo 3), por los países que integran el G8 y México, se puede observar la mayor coincidencia en las acciones implementadas por los distintos gobiernos en un mismo sector, el económico; pues tanto los países pertenecientes al G8 tomaron medidas semejantes entre sí, como las que se aplicaron en México.

Las políticas públicas estuvieron enfocadas en la reducción de las tasas de interés de los bancos centrales, la adquisición de valores por parte del gobierno con el objetivo de fortalecer la liquidez y el otorgamiento de líneas de crédito para empresas afectadas por la pandemia. Asimismo, Alemania, Japón y Rusia destacan entre el resto de los países analizados, debido a la activación de grandes paquetes económicos y presupuestos complementarios como respuesta a los problemas ocasionados por la emergencia sanitaria.

\section{CONCLUSIONES}

El Índice de Desarrollo Humano (IDH) que mide en una escala del 0 al 1 el bienestar de la población al tomar en cuenta la esperanza de vida, la educación y el ingreso per cápita de un país, permite reflejar las características con las cuales cada país que integra el G8 y México han enfrentado la crisis sanitaria por COVID19. En este caso los países del G8 conservan un valor entre 0.816 de Rusia al 0.939 de Alemania, mientras que México tiene un 0.767 que es menor que cualquiera de los países con los cuales se realizó este análisis.

De ahí que el análisis de las políticas públicas, en materia de bienestar social, económica y fiscal, refleje que ante las misma contingencia cada país reaccionó de acuerdo con sus recursos y capacidades; la reducción de las tasas de interés, la adquisición de valores para fortalecer la liquidez y otorgar líneas de crédito para empresas afectadas por la pandemia; la exención o aplazamiento de pago de impuestos, así como medidas de confinamiento y distanciamiento social, fueron las principales medidas de política pública implementadas en los países analizados.

Si bien puede ser que algunas políticas públicas contribuyeron de una mejor manera al manejo de la epidemia, es claro que cada gobierno formula sus estrategias basándose en los recursos con los que cuentan, el conocimiento que posea y de la experiencia de situaciones similares. Cada país está saliendo adelante con la adquisición de suficientes dosis de vacunas que permita atender a todos los habitantes, mitigar la pandemia y alcanzar el bienestar social que es el fin último de las políticas públicas. Estas iniciativas, sin duda, tendrán que ser revaloradas a la luz del avance de la pandemia y su consecuente mitigación. El paso siguiente será el desarrollo de estrategias que permitan la reactivación económica para que los países puedan experimentar nuevos periodos de auge económico y con ello, calidad de vida para los habitantes, también un fin último de las políticas públicas.

La línea de investigación e instrumento utilizado en este trabajo permite su aplicación en otros contextos; la comparación de las políticas públicas con los países latinoamericanos puede ser el origen de un siguiente proyecto que refleje el trabajo y la agenda de buen gobierno en la que se trabaja actualmente en América Latina para mitigar la pandemia y reactivar la economía.

También, pueden surgir otras líneas de investigación que permitan responder a preguntas, como por ejemplo: ¿cuál fue el 
efecto de la implementación de las distintas

otras.

políticas en cada país?, ¿qué país de los analizados presentó mejores resultados gracias a sus políticas públicas?, ¿a qué otro sectores pertenecen las políticas públicas que no fueron contempladas en esta investigación?, entre 


\section{REFERENCIAS}

Alzate, M., \& Romo, G. (2017). La agenda pública en sus teorías y aproximaciones metodológicas.

Una clasificación alternativa. Revista Enfoques: Ciencia Política y Administración Pública, XV(16),

16. http://www.redalyc.org/articulo.oa?id=96052974002

Arellano, D., \& Blanco, F. (2013). Políticas públicas y democracia. Vol. 1. Ciudad de México, México: Instutito Federal Electoral (IFE).

Asuntos Públicos Globales. (2020). Actualización: Estados Unidos continúa liderando la respuesta a la COVID-19. Departamento de Estado de los Estados Unidos. https://translations.state.gov/2020/05/01/actualizacion-estados-unidos-continua-liderando-larespuesta-a-la-covid-19/

Cadénas, C., \& Ruiz, D. (2009). ¿Qué es una política pública? IUS Revista Jurídica, 2-4. R http://taoppcomunicacion.weebly.com/unidad-3.html

Calduch, R. (1991). Relaciones internacionales. Madrid: Ediciones Ciencias Sociales. https://www.ucm.es/rrii-e-historia-global/libro-relaciones-internacionales

Díaz, F. J., \& Toro, A. I. (2020). SARS-CoV-2/COVID-19: el virus, la enfermedad y la pandemia. Medicina \& Laboratorio, 24(3), 184. https://doi.org/10.36384/01232576.268

Elizondo, M. R. (2017). Sociedad, economía y política del México actual. Centro de Desarrollo Docente e Innovación Educativa. Jalisco, México: Tecnológico de Monterrey. https://repositorio.tec.mx/handle/11285/622392

Fondo Monetario Internacional. (2020). Respuestas de política al Covid-19. https://www.imf.org/en/Topics/imf-and-covid19/Policy-Responses-to-COVID-19\#C

Fuentes, P. (31 de Julio de 2020). El impacto del covid-19 en Alemania. (I. T. México, Ed.) Foreing Affairs Latinoamérica. http://revistafal.com/el-impacto-del-covid-19-en-alemania/

González, M. (2018). El estudio de las políticas públicas: un acercamiento a la disciplina. SynthesiS, 102. https://revistas-colaboracion.juridicas.unam.mx/index.php/quid-iuris/article/view/17299

Hevia, C., \& Neumeyer, A. (2020). Un marco conceptual para analizar el impacto económico del COVID19 y sus repercusiones en las políticas. Universidad Torcuato Di Tella. PNUD América Latina y el

Caribe. https://www.latinamerica.undp.org/content/rblac/es/home/library/crisis_prevention_and_recover y/a-conceptual-framework-for-analyzing-the-economic-impact-of-covi.html

Instituto Tecnológico Autónomo de México. ITAM. (2006). http://ieie.itam.mx/g8.html

Jiménez, W. (Junio de 2012). El concepto de política y sus implicaciones en la ética pública: reflexiones a partir de Carl Schmitt y Norbert Lechner. CLAD Reforma y Democracia(53), 6-7. https://www.redalyc.org/articulo.oa?id=3575/357533685008

Lachera, E. (2004). Política y políticas públicas. Santiago: CEPAL; División de desarrollo social. https://www.fundacionhenrydunant.org/images/stories/biblioteca/PoliticasPublicas/Pol\%E2\%94\%9C\%C2\%A1tica\%20y\%20pol\%E2\%94\%9C\%C2\%A1ticas\%20p\%E2\% 94\%9C\%E2\%95\%91blicas

Ministerio de Asuntos Exteriores. (2019). Estados Unidos. Oficina de información diplomática. http://www.exteriores.gob.es/Documents/FichasPais/ESTADOSUNIDOS_FICHA\%20PAIS.pdf

Ministerio de Asuntos Exteriores. (2019). Francia. Oficina de Información Diplomática. http://www.exteriores.gob.es/Documents/FichasPais/FRANCIA_FICHA\%20PAIS.pdf

Ministerio de Asuntos Exteriores. (2019). México. Oficina de Información Diplomática. http://www.exteriores.gob.es/Documents/FichasPais/MEXICO_FICHA\%20PAIS.pdf

Ministerio de Asuntos Exteriores. (2020). Alemania. Oficina de información diplomática. 
http://www.exteriores.gob.es/Documents/FichasPais/ALEMANIA_FICHA\%20PAIS.pdf

Ministerio de Asuntos Exteriores. (2020). Canadá. Oficina de información informática. http://www.exteriores.gob.es/Documents/FichasPais/CANADA_FICHA\%20PAIS.pdf

Ministerio de Asuntos Exteriores. (2020). Italia. Oficina de Información Diplomática. http://www.exteriores.gob.es/Documents/FichasPais/ITALIA_FICHA\%20PAIS.pdf

Ministerio de Asuntos Exteriores. (2020). Japón. Oficina de Información Diplomática. http://www.exteriores.gob.es/Documents/FichasPais/JAPON_FICHA\%20PAIS.pdf

Ministerio de Asuntos Exteriores. (2020). Reino Unido. Oficina de Información Diplomática. http://www.exteriores.gob.es/Documents/FichasPais/REINOUNIDO_FICHA\%20PAIS.pdf

Ministerio de Asuntos Exteriores. (2020). Rusia. Oficina de Información Diplomática. http://www.exteriores.gob.es/Documents/FichasPais/RUSIA_FICHA\%20PAIS.pdf

Pastor, G. (2014). Elementos conceptuales y analíticos de las políticas públicas. Teoría y Práctica de las Políticas

Públicas,

18. https://www.academia.edu/21602795/Teor\%C3\%ADa_y_Pr\%C3\%A1ctica_de_las_Pol\%C3\%A Dticas_P\%C3\%BAblicas

Stein, E., \& Tommasi, M. (2006). La política de las políticas públicas. Política y gobierno, XII(02), 396397. http://www.politicaygobierno.cide.edu/index.php/pyg/article/viewFile/286/196

Tórtola, P., \& Monroy, L. (28 de febrero de 2020). Estudio de las políticas públicas. (U. Galileo, Ed.) 412.

https://www.academia.edu/42168638/ESTUDIO_DE_LAS_POL\%C3\%8DTICAS_P\%C3\%9A BLICAS

Velásquez, R. (2009). Hacia una nueva definición del concepto “política pública”. (U. d. Rosario, Ed.) Desafíos, 20(ISSN: 0124-4035), 149-187. http://www.redalyc.org/articulo.oa?id=359633165006 


\section{ANEXO 1}

Tabla 4. Políticas públicas en materia de bienestar social en México y el G8

Matriz de comparación de políticas públicas en materia de bienestar social

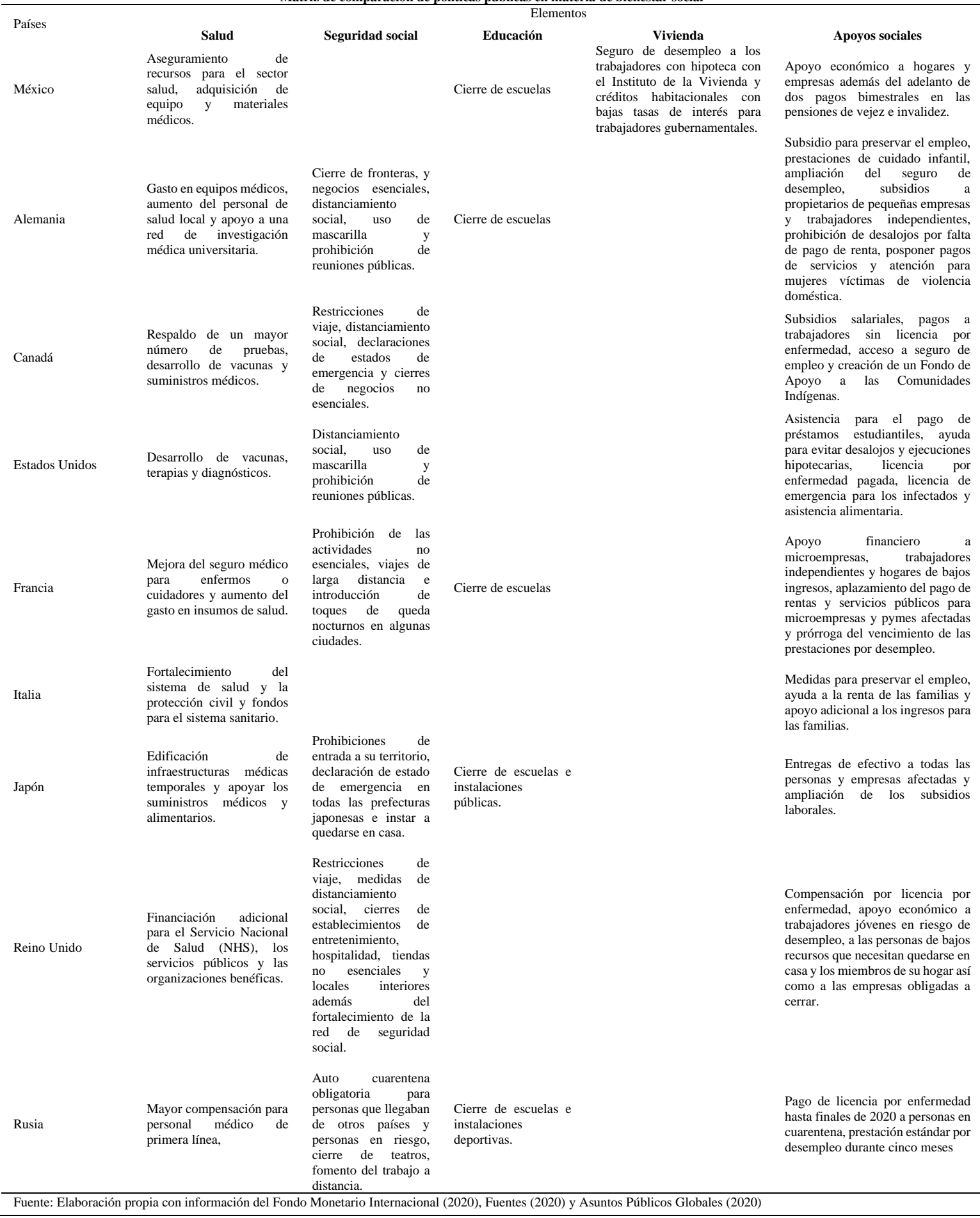




\section{ANEXO 2}

Tabla 5. Políticas públicas en materia fiscal en México y el G8

\begin{tabular}{|c|c|c|c|c|c|}
\hline \multicolumn{6}{|c|}{ Matriz de comparación de políticas públicas en materia fiscal } \\
\hline & & & Elementos & & \\
\hline Países & $\begin{array}{l}\text { Recaudación de } \\
\text { impuestos }\end{array}$ & Gasto público & Leyes o decretos & Aplicación de subsidios & $\begin{array}{c}\text { Préstamos federales e } \\
\text { hipoteca }\end{array}$ \\
\hline México & $\begin{array}{l}\text { Agilización de los } \\
\text { procesos de adquisiciones } \\
\text { y devoluciones del IVA. }\end{array}$ & $\begin{array}{l}\text { Agilizar los procesos de } \\
\text { licitación del gasto } \\
\text { público para asegurar el } \\
\text { cumplimiento del } \\
\text { presupuesto, programa de } \\
\text { austeridad en el gasto } \\
\text { público y reducción de los } \\
\text { salarios a servidores } \\
\text { públicos de altos niveles } \\
\text { de gobierno. }\end{array}$ & & & $\begin{array}{l}\text { Préstamos con } \\
\text { amortización opcional a } \\
\text { PYMES que mantienen } \\
\text { empleados en nómina, } \\
\text { empresas familiares y } \\
\text { préstamos personales a } \\
\text { tasas bajas demás de } \\
\text { normas contables } \\
\text { temporales que permiten } \\
\text { a los proveedores de } \\
\text { crédito aplazar préstamos } \\
\text { por hasta cuatro o seis } \\
\text { meses. }\end{array}$ \\
\hline Alemania & $\begin{array}{lrr}\text { Prórrogas fiscales } & y \\
\text { reducción temporal del } & \\
\text { IVA. } & & \end{array}$ & & Decreto de confinamiento & $\begin{array}{l}\text { Subsidio para preservar el } \\
\text { empleo, subsidios para } \\
\text { propietarios de empresas } \\
\text { y empleados afectados y } \\
\text { subsidios a propietarios } \\
\text { de pequeñas empresas y } \\
\text { trabajadores } \\
\text { independientes. }\end{array}$ & $\begin{array}{l}\text { Prórroga de pago en } \\
\text { préstamos destinados a } \\
\text { los hogares afectados. }\end{array}$ \\
\hline Canadá & $\begin{array}{l}\text { Aumento en los créditos } \\
\text { fiscales GST y } \\
\text { aplazamientos } \\
\text { impuestos. }\end{array}$ & & $\begin{array}{l}\text { Emisión de una } \\
\text { "orientación a futuro", en } \\
\text { la que se comunica que no } \\
\text { se subirá la tasa de interés } \\
\text { hasta que la recuperación } \\
\text { esté bien encaminada. }\end{array}$ & & $\begin{array}{lr}\text { Apoyo a Farm } & \text { Credit } \\
\text { Canadá que permitirá una } \\
\text { capacidad } & \text { crediticia } \\
\text { adicional } & \text { para } \\
\text { productores, } & \\
\text { agroindustrias } & \text { y } \\
\text { procesadores } & \text { de } \\
\text { alimentos. } & \end{array}$ \\
\hline Estados Unidos & $\begin{array}{lcr}\text { Suspensión } & \text { de } & \text { la } \\
\text { recaudación } & \text { de } & \text { los } \\
\text { impuestos } & \text { sobre } & \text { la } \\
\text { nómina. } & & \end{array}$ & & $\begin{array}{lr}\text { Ley de mejora de la } \\
\text { atención médica, Ley de } \\
\text { Ayuda y } & \text { Seguridad } \\
\text { Económica } & \text { por } \\
\text { Coronavirus } & \text { ("Ley } \\
\text { CARES") y Ley de } \\
\text { Apropiaciones } \\
\text { Suplementarias. }\end{array}$ & $\begin{array}{l}\text { Subsidios a préstamos de } \\
\text { la administración de } \\
\text { pequeñas empresas. }\end{array}$ & $\begin{array}{l}\text { Fannie Mae y Freddie } \\
\text { Mac } \\
\text { hipotecarias) anunciaron } \\
\text { una tolerancia hipotecaria } \\
\text { durante } 12 \text { meses y } \\
\text { desaparición de cargos } \\
\text { por demora. }\end{array}$ \\
\hline Francia & $\begin{array}{l}\text { Aplazamiento del pago de } \\
\text { impuestos y seguridad } \\
\text { social y devolución } \\
\text { acelerada de créditos } \\
\text { fiscales. }\end{array}$ & & Decreto de confinamiento & & \\
\hline Italia & $\begin{array}{l}\text { Aplazamientos } \\
\text { impuestos y pago de } \\
\text { facturas de } \\
\text { públicos. }\end{array}$ & & Decreto "Curar Italia" & & $\begin{array}{l}\text { Moratoria sobre los } \\
\text { reembolsos de préstamos } \\
\text { para hogares y PYMES } \\
\text { así como sobre hipotecas } \\
\text { y garantías estatales sobre } \\
\text { préstamos a todas las } \\
\text { empresas. }\end{array}$ \\
\hline Japón & \begin{tabular}{lr}
\multicolumn{3}{l}{ Aplazamiento del pago de } \\
impuestos & y \\
contribuciones a & la \\
seguridad social. &
\end{tabular} & & & $\begin{array}{l}\text { Ampliación de los } \\
\text { subsidios laborales }\end{array}$ & $\begin{array}{l}\text { Aplazamiento del pago de } \\
\text { préstamos de } \\
\text { instituciones financieras } \\
\text { públicas y privadas. }\end{array}$ \\
\hline Reino Unido & $\begin{array}{l}\text { Exenciones fiscales para } \\
\text { pequeñas empresas y } \\
\text { empresas de los sectores } \\
\text { más afectados, } \\
\text { reducciones temporales } \\
\text { de la tasa de IVA para } \\
\text { hospitalidad, alojamiento } \\
\text { y atracciones y el } \\
\text { impuesto a } \\
\text { transacciones las } \\
\text { inmobiliarias. }\end{array}$ & $\begin{array}{lr}\begin{array}{l}\text { Aumento del } \\
\text { público }\end{array} & \text { gasto } \\
\text { infraestructura. } & \text { en }\end{array}$ & & & $\begin{array}{l}\text { Iniciativa para ofrecer un } \\
\text { congelamiento de pagos } \\
\text { en préstamos y tarjetas de } \\
\text { crédito por hasta tres } \\
\text { meses. }\end{array}$ \\
\hline Rusia & $\begin{array}{l}\text { Prórroga de pago de } \\
\text { impuestos para las } \\
\text { empresas más afectadas, } \\
\text { aplazamiento de las } \\
\text { cotizaciones sociales para } \\
\text { las PYMES afectadas, } \\
\text { reembolso de impuestos a } \\
\text { los autónomos }\end{array}$ & & Decreto de confinamiento & & $\begin{array}{l}\text { Aplazamiento del pago de } \\
\text { préstamos a ciudadanos y } \\
\text { PYMES afectados }\end{array}$ \\
\hline
\end{tabular}




\section{ANEXO 3}

Tabla 6. Políticas públicas en materia económica en México y el G8

Matriz de comparación de políticas públicas en materia económica

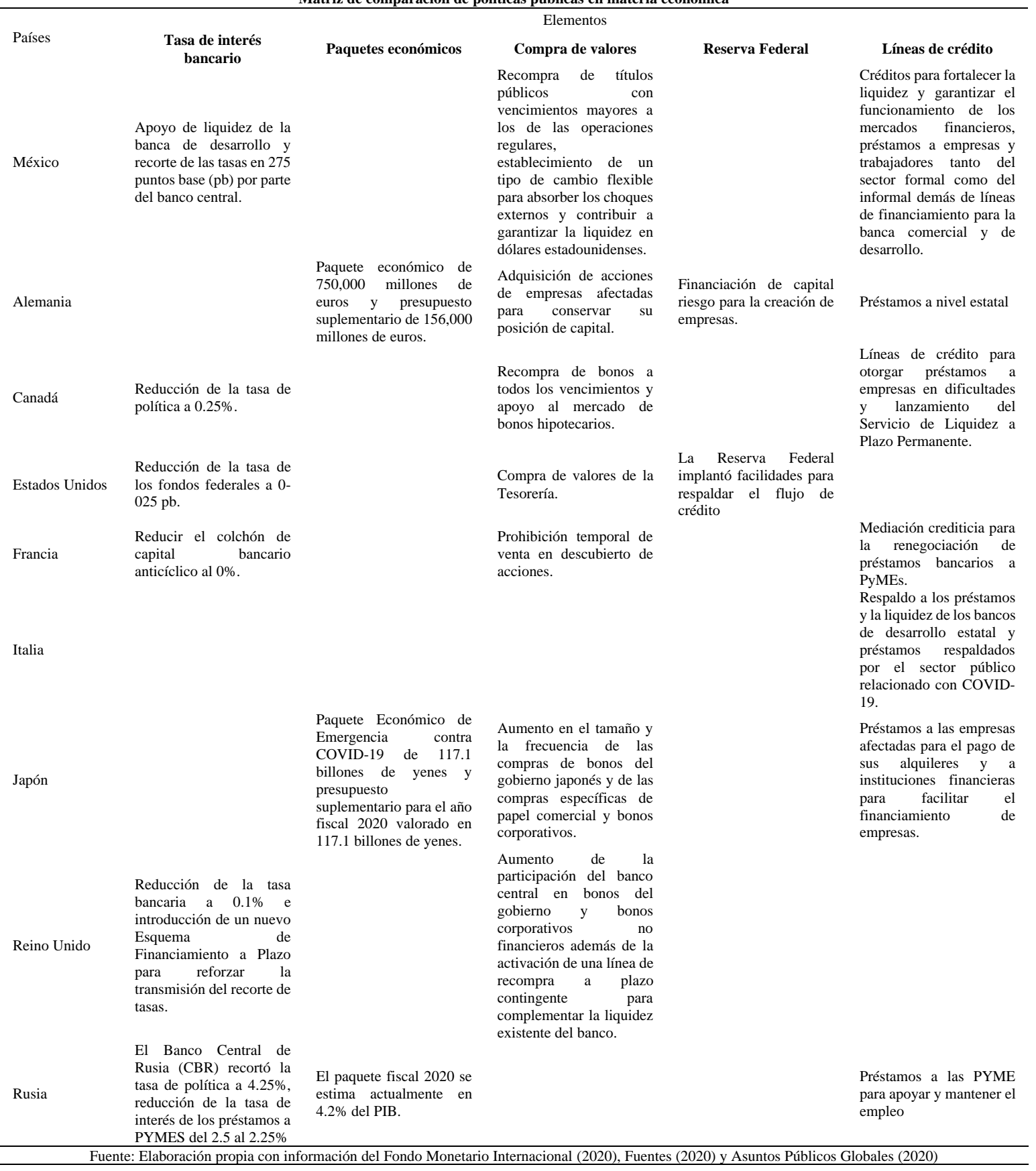

